\title{
COMPROMETIMENTO DA QUALIDADE DA ÁGUA SUBTERRÂNEA POR NITRATOS
}

NUNES, Marcos Leandro Alves ${ }^{1}$ GOMES, Josiane de Brito ${ }^{1}$ WEBLER, Alberto Dresch ${ }^{1}$ ANDRADE, Leonardo Rosa ${ }^{1}$ MARCHETTO, Margarida ${ }^{2}$

RESUMO: Uma parcela considerável da população de Ji-Paraná supre suas necessidades diárias de água em sistemas alternativos de abastecimento, com água proveniente do manancial subterrâneo. Estudos evidenciam que este recurso é suscetível à contaminação e/ou poluição por fontes de poluição pontual, como as fossas, amplamente utilizadas na área urbana deste município. Áreas de plantio de hortaliças são potenciais fontes difusas de contaminação da água e informações sobre o seu efeito na qualidade da água subterrânea ainda são incipientes. Sendo assim, esse estudo propõe avaliar a qualidade da água em localidades próximas a horta, na cidade de Ji-Paraná - RO, a fim de elucidar o impacto que as práticas de fertilização têm na qualidade da água. Desta forma, avaliou-se as concentrações dos íons nitrato e nitrito, além dos parâmetros $\mathrm{pH}$, condutividade elétrica e oxigênio dissolvido, nos períodos de maior e menor precipitação. Ao analisar os resultados da pesquisa, comparando os pontos amostrais à montante e próximos à horta, percebe-se que as maiores concentrações de nitratos quanto de nitrito ocorrem nos pontos adjacentes à área de cultivo. As maiores concentrações para ambos os parâmetros ocorrem na estação seca, valores médios superiores ao período chuvoso em 52,77\% para o nitrato e 158,86\% para o nitrito. Quanto aos demais parâmetros, não há uma correlação clara entre área de plantio de hortaliças e seus valores.

Palavras-chave: Horta. Fertilização. Contaminação de manancial.

\section{THE COMPROMISED ON THE QUALITY OF GROUNDWATER BY NITRATE}

SUMMARY: A large number Ji-Paraná's population supplies your daily needs with groundwater, an alternative water supply, and a important source of drinking water. Studies showed that this drinking water are vulnerable to pollution and/or to contamination from point-sources of pollution such as septic tanks, very common in the urban area's Ji-Paraná. Cropland are nonpoints-source pollution to water and information about its effect on groundwater quality are still incipient. Therefore, this research proposes to assess the water quality in points close a small market garden in the Ji-Paraná's city, State of Rondônia, Western Amazonia, aiming to explain that fertilisers used incorrectly can affect the drinking water quality. So, the objetive of this study was to evaluated the concentrations of nitrate and nitrite ions, thus as the parameters $\mathrm{pH}$, electrical conductivity and dissolved oxygen during the rainy season and the dry season. The results's the research, comparing the sample points upstream and close to the marhet garden, indicated that the highest concentrations of nitrate and nitrite occur at points near to the area of cultivation. The highest concentrations for both parameters were observed in the dry season, higher than the averages's rainy season, in percentages, $52,77 \%$ to nitrate and $158,86 \%$ for nitrite. Considering the others parameters, there are not a clear correlation between the market garden and their values.

Keywords: Market garden. Fertilizer. Contamination of water source.

\section{INTRODUÇÃO}

O intenso desenvolvimento da atividade agrícola sob áreas de mananciais tem causado grande preocupação, uma vez que tal prática potencializa a vulnerabilidade natural dessas áreas às contaminações.

\footnotetext{
${ }^{1}$ Graduandos em Engenharia Ambiental pela Universidade Federal de Rondônia, Campus de Ji-Paraná, e-mail: marcobatarelli@hotmail.com, josinha_brito@hotmail.com, betowebler@ibest.com.br, superleofera@hotmail.com.

${ }^{2}$ Universidade Federal de Mato Grosso, Campus de Cuiabá, e-mail: marchetto_ro@gmail.com
} 
O conhecimento da influência exercida por essas atividades sobre os recursos naturais é de fundamental importância para assegurar a qualidade da água (PESSOA, et al., 2003).

O contínuo incremento do uso das águas subterrâneas tem sido procedente principalmente da ocupação de áreas menos providas de reservas de águas superficiais, do abastecimento de água para irrigação e da busca por captação de água de melhor qualidade. Em Ji-Paraná, o manancial subterrâneo abastece uma parcela significativa da população, que afirma que ambos os requisitos, quantidade e qualidade estão presentes nesta fonte.

De fato, em princípio os recursos hídricos subterrâneos são menos suscetíveis a poluição e/ou contaminação se comparados aos corpos d'água superficial. No entanto, a qualidade dessas águas é comprometida ao ocorrer à percolação de insumos agrícolas como agrotóxicos e fertilizantes, além de efluentes domésticos e excrementos de animais nas águas subterrâneas ou, diretamente, nos poços artesianos (MIRLEAN et al., 2005).

Embora, não seja o único agente responsável pela perda da qualidade da água, a agricultura contribui fortemente à contaminação de mananciais subterrâneos, pois tende a aumentar a concentração de sais no solo e na água. Dentre os íons lixiviados, o nitrato e o cloreto são os que ocorrem com maior frequência, havendo uma predominância do primeiro.

O nitrato é um dos íons mais encontrados em águas naturais, geralmente ocorrendo em baixos teores nas águas superficiais, mas podendo atingir altas concentrações em águas profundas. $\mathrm{O}$ seu consumo através das águas de abastecimento está associado a dois efeitos adversos à saúde: a indução à metemoglobinemia, também conhecida como síndrome do "bebê azul", e a formação potencial de nitrosaminas e nitrosamidas carcinogênicas (ALABURDA; NISHIHARA, 1998). Essa problemática é preocupante e digna de notoriedade, uma vez que em áreas exploradas com agricultura irrigada, a concentração de $\mathrm{N}^{-N_{3}}$ nas águas do lençol freático, pode exceder a 200mg/L (CHOWDARY et al., 2005).

Os estudos sobre a qualidade do lençol freático de Ji-Paraná ainda são incipientes e as poucas pesquisas realizadas evidenciam contaminação por esgoto doméstico. A ausência de um sistema de coleta e tratamento de efluentes sanitários preocupa, pois tais águas residuárias são dispostas no solo, em fossas com profundidades próximas ao nível do manancial subterrâneo. Acondicionar efluentes em fossas não impede a poluição do lençol freático. Referente a este assunto, Silva e Dourado (2008) constataram que as águas subterrâneas da zona urbana de Ji-Paraná não são indicadas para abastecimento humano, sem tratamento prévio, possivelmente, devido a sua degradação por contaminantes oriundos das fossas.

Além, da contaminação do lençol freático pelo sistema de disposição de esgoto doméstico in situ, fontes de poluição difusa, como as provenientes de áreas cultivadas preocupam. Percebe-se, dessa forma, que a qualidade da água de abastecimento público de Ji-Paraná vem sendo deteriorada e garantir um padrão mínimo de qualidade da água pode evitar inúmeras patologias de veiculação hídrica que oferecem risco à saúde de seus usuários. Desenvolver estudos com o intento de identificar as possíveis fontes de contaminação da água subterrâneas é de grande importância para a preservação da qualidade da água.

Pelo exposto, há uma enorme relevância em pesquisar a possível contaminação nas águas subterrâneas. Sendo assim, esse estudo propõe avaliar a qualidade da água em localidades próximas a horta na cidade de Ji-Paraná - RO, a fim de elucidar o impacto das práticas de fertilização têm na qualidade da água. Desta forma, avaliou-se as concentrações dos íons nitrato e nitrito, além dos parâmetros pH, condutividade elétrica e oxigênio dissolvido, em quatro campanhas ao longo de 2010.

\section{MATERIAIS E MÉTODOS}

\section{Área de estudo}


A horta estudada localiza-se às margens da Avenida Brasil, saída para o aeroporto municipal de JiParaná, cidade esta, situada no centro-leste do estado de Rondônia, Amazônia Ocidental (Figura 1). Sua

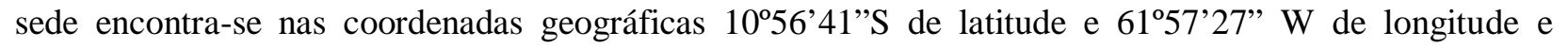
distante $373 \mathrm{Km}$ de Porto Velho, a capital do estado.

Figura 1 - Pontos amostrais próximo à horta

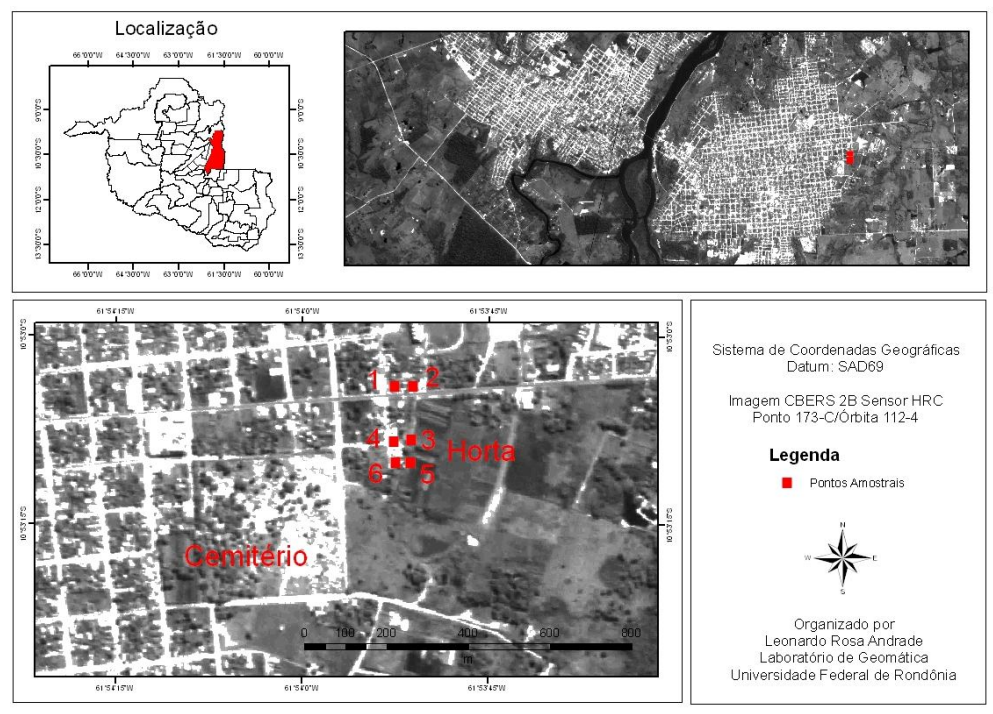

Segundo classificação de köppen, o clima típico da região é o tropical chuvoso, com precipitação média anual entorno de $2.000 \mathrm{~mm}$, com períodos de maior índice pluviométrico entre os meses de novembro a março e os menores índices nos meses de junho a setembro (Figura 2).

Figura 2 - Precipitação média anual na cidade de Ji-Paraná/RO.

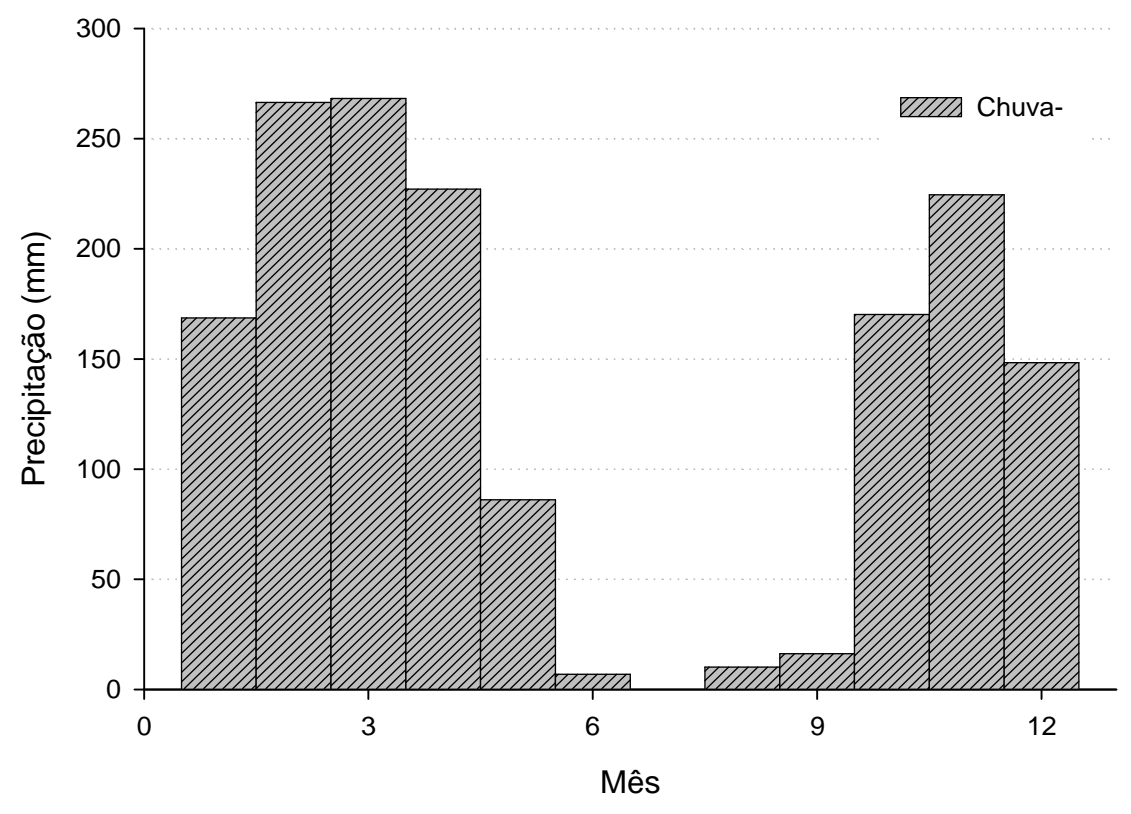

\section{Características geológicas, geomorfológicas e aspectos construtivos dos pontos amostrais}

A área em estudo é constituída de rochas cristalinas como gnaisses paraderivados e ortognaisses, compostos principalmente de granítica e granodiorítica. Os latossolos predominantes são os vermelhoamarelos e amarelos, podzólico vermelho-amarelo, geralmente pobres e ácidos. As áreas de entorno do rio 
Ji-Paraná e demais córregos são caracterizadas pela predominância de sedimentos aluvionares quaternários e coberturas superficiais cenozóicas.

No município os solos são tipicamente arenosos. Amostras do perfil da zona insaturada do solo demonstram que a fração areia predomina nos solos de todos os bairros estudados. Silva (2008) ponderou que, no bairro Nova Brasília, 50\% das amostras de solos são constituídas de substrato arenoso, 33,3\% de areno-síltico e 16,6\% silte-arenoso. Em suma, prevalecem perfis constituídos por gnaisse, que sustentam argila, silte areia grossa e fina, sendo que, o que distingue pontos em diferentes localizações é a espessura de cada camada.

A topografia de Ji-Paraná é tipicamente ondulada com cota mínima de $130 \mathrm{~m}$ e máxima de $550 \mathrm{~m}$, e o aquífero é classificado como fraturado descontínuo livre, apresentando cobertura sedimentar coluvionares (argilo-arenoso (MORAES, 1998).

\section{Métodos amostrais e medidas de campo}

Foram selecionados seis pontos amostrais (poços) próximos à horta. Os primeiros dois pontos localizam-se a montante da horta, enquanto, os demais são adjacentes e à jusante da área estudada.

As amostras foram coletadas de acordo com a metodologia proposta no Standard Methods for the Examination of Water and Wastewater, a cada três meses, totalizando quatro campanhas distribuídas ao longo do ano de 2010. Com o auxílio de uma garrafa de Niskin de 5 litros coletou alíquotas de $500 \mathrm{ml}$ conservadas com thymol, no ato da coleta, para as análises dos íons nitrato e nitrito. Os parâmetros físicoquímicos como pH, oxigênio dissolvido (OD), e condutividade elétrica foram medidos in situ com o medidor multiparâmetros portátil, marca Hanna Instruments, modelo HI 9828.

\section{Métodos analíticos dos íons nitrato e nitrito}

A espectrometria de absorção ultravioleta é bastante utilizada para mensurar a absorção de luz ultravioleta por diferentes substâncias. Na faixa de onda de $220 \mathrm{~nm}$, permitem determinação do nitrato. Todavia, matéria orgânica absorve ondas de $220 \mathrm{~nm}$ e de $275 \mathrm{~nm}$, porém, o nitrato não absorve esta última. Uma segunda medida, em $275 \mathrm{~nm}$, é necessária para que o valor de absorbância referente à matéria orgânica seja subtraída. Assim, a concentração de nitrato foi determinada pela leitura da amostra em comprimentos de ondas em $220 \mathrm{~nm}$ subtraída do dobro da leitura em $275 \mathrm{~nm}$ e a concentração de nitrito pela leitura da amostra na faixa de $543 \mathrm{~nm}$. Todas as amostras foram analisadas conforme a metodologia proposta no Standard Methods for the Examination of Water and Wastewater.

\section{RESULTADOS E DISCUSSÃO}

Serão apresentadas as características dos poços rasos e da área a sua volta bem como os resultados das análises físico-químicas referentes à qualidade da água nos diferentes poços. Cada parâmetro é apresentado e discutido.

\section{Características construtivas dos poços}

As principais características dos 6 poços estudados estão resumidas na Tabela 1. Nota-se que esses pontos de captação de água são relativamente protegidos, sua área de entorno possui calçamento, o poço é bem vedado e revestido com manilhas. Tais características minimizam o risco de contaminação da fonte de água pela entrada de insetos, infiltração de cargas poluentes pontuais, próximas aos poços e o 
desprendimento de partículas das paredes dos mesmos. Todos apresentam uma distância maior que 15 metros em relação às fossas, sendo superior a distância mínima recomendada pela Fundação Nacional da Saúde - FUNASA (2004) para evitar a degradação da qualidade do manancial subterrâneo pelos efluentes contidos nas fossas. Na região é comum a utilização de poço raso escavado manualmente e suas características assemelham-se as apresentadas na Tabela 1.

Tabela 1. Características dos poços rasos e da área a sua volta

\begin{tabular}{cccccc}
\hline \multirow{5}{*}{ Pto } & \multicolumn{5}{c}{ Características construtivas } \\
\cline { 2 - 6 } & $\begin{array}{c}\text { Profundidade } \\
(\mathrm{m})\end{array}$ & Revestimento & $\begin{array}{c}\text { Calçamento } \\
\left(\mathrm{m}^{2}\right)\end{array}$ & Vedação & $\begin{array}{c}\text { Fossa mais } \\
\text { próxima (m) }\end{array}$ \\
1 & 8 & Manilha & Superior a 1 & Adequada & 16 \\
2 & 14 & Manilha & Superior a 1 & Adequada & 20 \\
\hline 3 & 12 & Manilha & Superior a 1 & Adequada & 18 \\
\hline 4 & 8 & Manilha & Superior a 1 & Adequada & 16,4 \\
5 & 10 & Manilha & Superior a 1 & Adequada & 22 \\
\hline 6 & 16 & Manilha & Superior a 1 & Adequada & 17,3 \\
\hline
\end{tabular}

\section{Qualidade da água subterrânea}

Os parâmetros físico-químicos da água dos poços, nos períodos de maior e menor precipitação, denominados como períodos chuvoso e seco são apresentados na Tabela 2. Para os 6 poços estudados o pH variou de 6,41 a 7,08, com valor médio de 6,82, na estação chuvosa. Na estação seca o pH variou de 6,33 a 7,16, com valor médio de 6,81. A amplitude dos valores de $\mathrm{pH}$ foi ligeiramente maior na estação seca, no entanto, percebe-se que os valores médios pouco diferem-se.

A sazonalidade tem pouca influência nos valores deste parâmetro, confirmado por teste estatístico (teste t), e este aponta que não há evidências para supor que os valores de $\mathrm{pH}$ sejam diferentes entre os períodos chuvoso e seco. Ao analisar os valores de pH da Tabela 2 verifica-se que todos os poços estão de acordo com a faixa 6-9,5 estabelecida na Portaria CONAMA n ${ }^{\circ}$ 518/2007.

Em relação ao oxigênio dissolvido (OD) em água, este apresentou baixos valores nos 6 pontos estudados, em ambas as estações. Embora, sejam pífias as concentrações de OD, tais valores não oferecem risco a saúde de seus usuários. Os baixos valores de OD são característicos das águas naturais da região, tanto subterrânea quanto superficial, e muitas vezes, não expressam contaminação por material orgânico.

Tabela 2. Resultados das análises físico-químicas

(Continua)

\begin{tabular}{|c|c|c|c|c|}
\hline Coleta & Pto & Coordenadas Geográfica & pH & OD $(\mathrm{mg} / \mathrm{L})$ \\
\hline \multirow{5}{*}{$\begin{array}{l}0 \\
0 \\
0 \\
\Xi \\
0 \\
0 \\
0 \\
0 \\
0 \\
0 \\
0\end{array}$} & 1 & $\begin{array}{c}10^{\circ} 53^{\prime} 5.58 " \mathrm{~S} \\
61^{\circ} 53^{\prime} 50.87^{\prime \prime O}\end{array}$ & 6,94 & 2,12 \\
\hline & 2 & $\begin{array}{c}10^{\circ} 53^{\prime} 5.48 " \mathrm{~S} \\
61^{\circ} 53^{\prime} 53.82^{\prime \prime} \mathrm{O}\end{array}$ & 6,66 & 1,98 \\
\hline & 3 & $\begin{array}{l}10^{\circ} 53^{\prime} 10.86^{\prime \prime S} \\
61^{\circ} 53^{\prime} 53.84^{\prime \prime O}\end{array}$ & 6,41 & 1,94 \\
\hline & 4 & $\begin{array}{l}10^{\circ} 53^{\prime} 10.82^{\prime \prime S} \\
61^{\circ} 53^{\prime} 54.15^{\prime \prime O}\end{array}$ & 7,08 & 1,96 \\
\hline & 5 & $\begin{array}{l}10^{\circ} 53^{\prime} 10.99 " \mathrm{~S} \\
61^{\circ} 53^{\prime} 53.66^{\prime \prime O}\end{array}$ & 6,79 & 2,82 \\
\hline
\end{tabular}


Tabela 2. Resultados das análises físico-químicas

(Conclusão)

\begin{tabular}{|c|c|c|c|c|}
\hline & 6 & $\begin{array}{l}10^{\circ} 53^{\prime} 11.80^{\prime \prime} \mathrm{S} \\
61^{\circ} 53^{\prime} 54.26^{\prime \prime} \mathrm{O}\end{array}$ & 7,02 & 2,41 \\
\hline \multirow{6}{*}{$\begin{array}{l}8 \\
8 \\
\tilde{N} \\
8 \\
8 \\
0 \\
0 \\
0\end{array}$} & 1 & $\begin{array}{c}10^{\circ} 53 ' 5.58^{\prime \prime S} \\
61^{\circ} 53^{\prime} 50.87^{\prime \prime O}\end{array}$ & 6,61 & 1,66 \\
\hline & 2 & $\begin{array}{c}10^{\circ} 53^{\prime} 5.48 " \mathrm{~S} \\
61^{\circ} 533^{\prime} 53.82^{\prime \prime} \mathrm{O}\end{array}$ & 7,16 & 2,14 \\
\hline & 3 & $\begin{array}{l}10^{\circ} 53^{\prime} 10.86 " \mathrm{~S} \\
61^{\circ} 53^{\prime} 53.84^{\prime \prime O}\end{array}$ & 6,90 & 1,62 \\
\hline & 4 & $\begin{array}{l}10^{\circ} 53^{\prime} 10.82^{\prime \prime} \mathrm{S} \\
61^{\circ} 53^{\prime} 54.15^{\prime \prime O}\end{array}$ & 7,04 & 1,87 \\
\hline & 5 & $\begin{array}{l}10^{\circ} 53^{\prime} 10.99^{\prime \prime} \mathrm{S} \\
61^{\circ} 53^{\prime} 53.66^{\prime \prime O}\end{array}$ & 6,33 & 2,21 \\
\hline & 6 & $\begin{array}{l}10^{\circ} 53^{\prime} 11.80^{\prime \prime S} \\
61^{\circ} 53^{\prime} 54.26^{\prime \prime O}\end{array}$ & 6,82 & 2,18 \\
\hline
\end{tabular}

A condutividade elétrica (CE) da água variou entre 111 a $164 \mu \mathrm{S} / \mathrm{cm}$ nos pontos estudados, com média de 143,6 na época de chuvas e entre 128 a 203, com média de 167,5 na época de estiagem. Segundo Melo et al. (2007) a condutividade elétrica é utilizada para expressar a concentração de sais solúveis na água, e o aumento dos valores desse parâmetro denota o incremento de sais solúveis em água ou a sua concentração. A análise da Figura 3 evidencia que com o início das chuvas há um declínio nos valores de condutividade elétrica. Isto ocorre devido à diluição dos poluentes, enquanto na estação seca há aumento da concentração destes, alterando a qualidade da água. A faixa de valores apresentados expressa ser de baixa salinidade a água dos poços, conforme define o autor citado. Leite et al. (2010) explica que os ecossistemas florestais da região amazônica, pouco antropizados, apresentam baixos valores de condutividade e reforça que valores mais elevados de condutividade estão associados a áreas onde predominam atividades agrícolas, semelhante a área estudada em que os maiores valores de CE foram observados nos poços próximo à horta.

Figura 3 - Condutividade elétrica da água subterrânea.

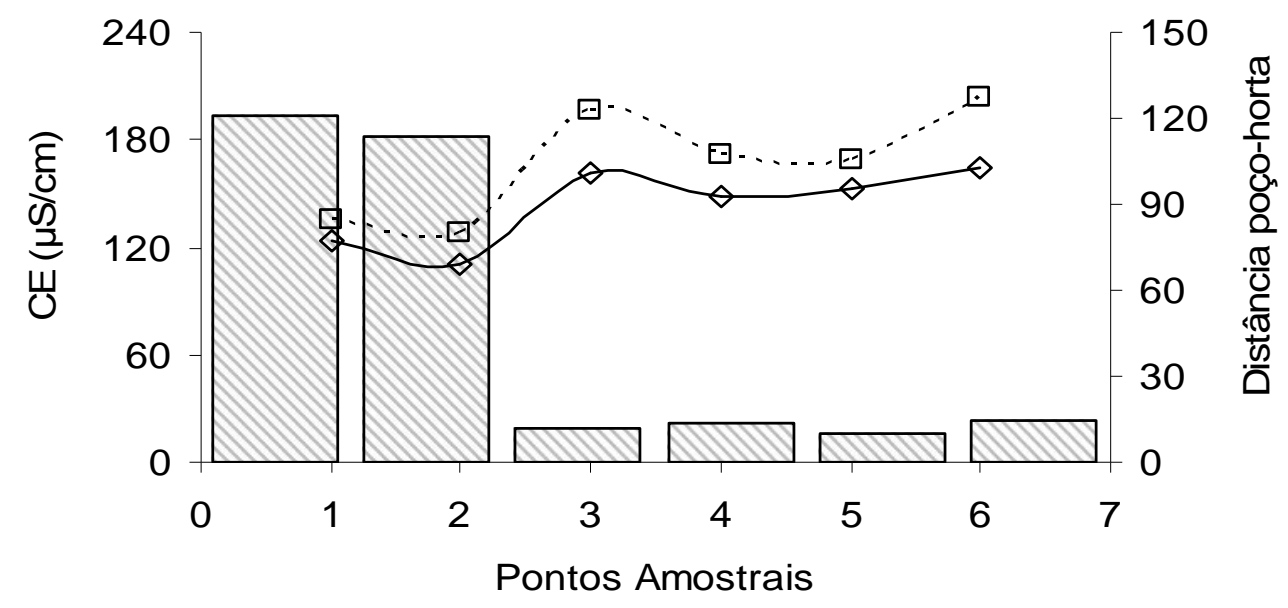

Distância poço-horta $\multimap$ Estação chuvosa - - - - - Estação seca

Os valores de nitrato $\left(\mathrm{NO}_{3}{ }^{-}\right)$nos pontos estudados variaram entre 3,4 a 15,1, com média de 9,36 $\mathrm{mg} / \mathrm{L}$, ao período chuvoso. Na seca, os valores oscilaram entre 5,5 e 26,2, com média de14,3. Ao analisar 
os valores dos compostos nitrogenados (Tabela 2), nos pontos à montante e adjacente à horta, nota-se que o seu teor é maior nos poços localizados próximos a horta. Nos dois primeiros pontos, à montante da horta, os valores foram inferiores ao máximo permitido em água de abastecimento público, ou seja, 10 $\mathrm{mg} / \mathrm{L}$, tanto na estação chuvosa quanta na seca. A constatação anterior é melhor entendida ao analisar a Figura 4. Ao observar esta figura depreende-se que a qualidade da água, em relação a concentração de nitrato, é melhor na estação chuvosa em todos os pontos amostrais. No período de estiagem ocorre um aumento da concentração do íon nitrato na água, sendo maior no ponto 3, o mais próximo da horta.

Figura 4a - Variação da concentração de água subterrânea na estação chuvosa.
Figura 4b - Variação da concentração de nitrato na água subterrânea na estação seca.

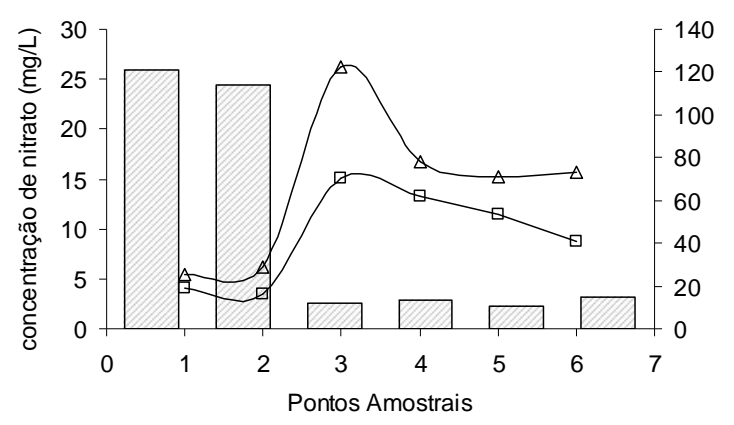

$\square$ Distância poço-horta $\square-$ Estação chuvosa $\triangle$ Estação seca

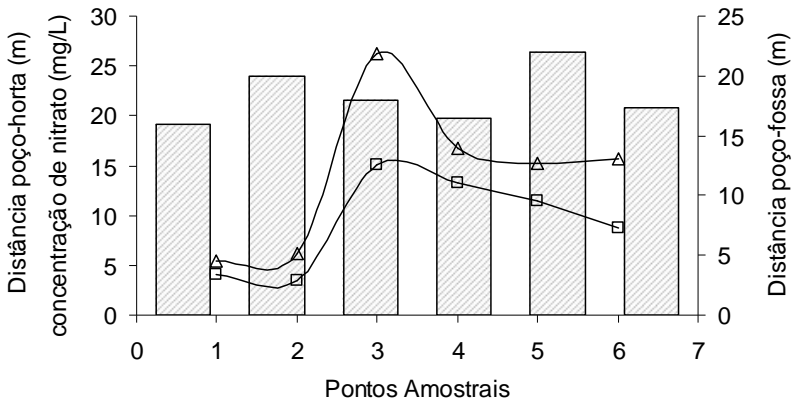

Distância poço-fossa $\square$ Estação chuvosa $\triangle$ Estação seca

Os poços estão relativamente distantes das fossas, acima de 15 metros (Figura 4b), como preconiza a FUNASA (2004). Desta forma, presume-se que a principal fonte de compostos nitrogenados é oriunda da área cultivada por hortaliças, provavelmente decorrente dos fertilizantes utilizados na mesma. Tal constatação é reforçada ao verificar os valores de $\mathrm{NO}_{3}{ }^{-}$nos pontos amostrais. A montante da horta a concentração de $\mathrm{NO}_{3}^{-}$foi inferior aos pontos localizados a jusante dessa área, indicando influencia da horta nos valores de nitrato. Em relação ao exposto, Resende (2002) esclarece que o nitrato está presente naturalmente no solo em baixas concentrações, no entanto, altas concentrações podem ser provenientes de diferentes fontes. $\mathrm{O}$ mesmo autor ainda elucida que o aumento de nitrato no solo e na água subterrânea, em áreas cultivadas, decorre do superdimensionamento de quantidades de fertilizantes, acima da capacidade de aproveitamento das culturas.

A poluição das águas por nitratos ocorre em outros pontos da cidade de Ji-Paraná e em outros municípios de sua microrregião. De acordo com Silva et al. (2009), o bairro Nova Brasília, o mais populoso de Ji-Paraná, os níveis de nitrato em alguns poços foram superiores a $200 \mathrm{mg} / \mathrm{L}$. Diferentemente dos pontos estudados, as fossas são as possíveis causas para os elevados valores de $\mathrm{NO}_{3}^{-}$, conforme conclui Santos.

A presença de nitrato na água de abastecimento humano é preocupante, pois este elemento afeta negativamente a saúde de seus usuários. Conforme esclarecem Alaburda e Nishihara (1998) o nitrato causa a metemoglobinemia, doença que torna a hemácia incapaz de transportar oxigênio para as células. Os autores ainda frisam que pesquisas apontam o nitrato como o responsável por neoplasias gastrintestinais. Opondo-se as ideias de Alaburda e Nishihara, Luz et al. (2008) defendem que não há estudos conclusivos sobre o efeito do nitrato na saúde humana e em muitos casos, dietas ricas neste nutriente, podem ser benéficas à saúde. Rondônia, estado onde os diagnósticos de carcinomas estomacais possuem o segundo maior índice do país (MS, 2011) as informações citadas anteriormente impressionam.

Referente ao nitrito $\left(\mathrm{NO}_{2}{ }^{-}\right)$, este apresentou comportamento similar ao nitrato. Na estação chuvosa, todos os pontos, como se observa na Figura 5, apresentaram menor concentração do parâmetro, com 
valores entre 0,020 a 0,081 e média de 0,047. Enquanto, na estação seca houve o aumento desse parâmetro para todos os pontos. Todavia, diferentemente do íon nitrato, o $\mathrm{NO}_{2}{ }^{-}$apresentou valores inferiores ao máximo permitido $\left(1 \mathrm{mg} / \mathrm{L} \mathrm{N}-\mathrm{NO}_{2}{ }^{-}\right)$, em ambas as estações. Ao se comparar os valores à montante e à jusante da horta nota-se que os valores de $\mathrm{NO}_{2}{ }^{-}$são maiores nas proximidades da horta e a relação poçofossa parece ter pouca influência para o parâmetro monitorado no período do estudo.

Figura 5a - Variação da concentração de na água subterrânea na estação chuvosa.
Figura 5b - Variação da concentração de nitrito nitrito na água subterrânea na estação seca.
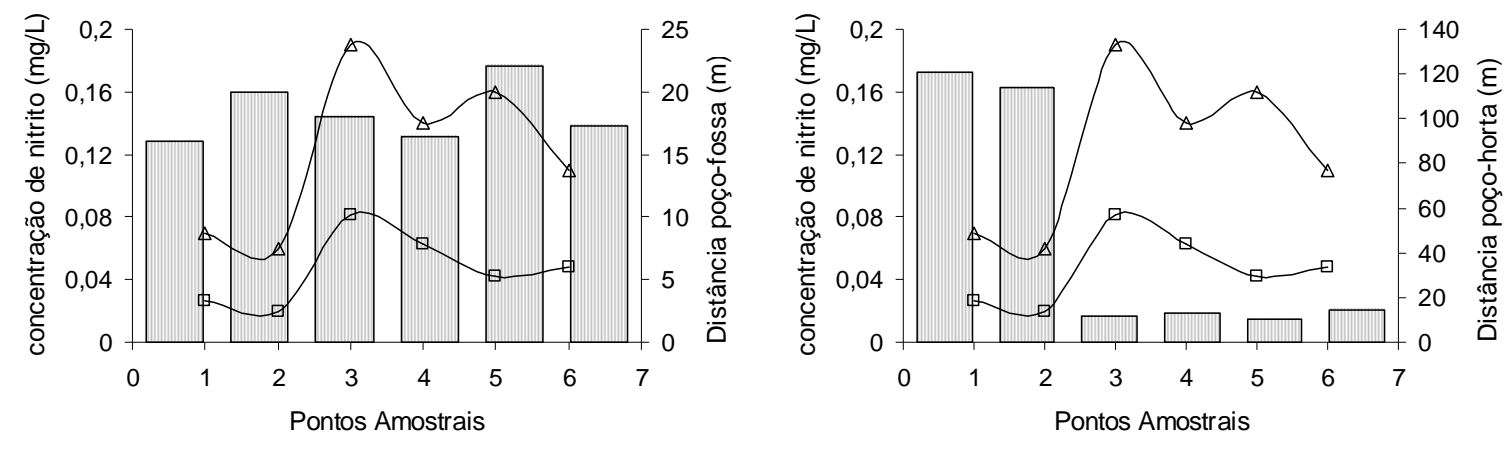

$\square$ Distância poço-fossa $\square$ Estação chuvosa $\triangle$ Estação seca

$\square$ Distância poço-horta $\square$ Estação chuvosa $\triangle$ Estação seca

Mapear e identificar as potenciais fontes de poluição da água é o primeiro passo e o mais básico para o desenvolvimento de uma política de gerenciamento do espaço urbano. No município de Ji-Paraná já foi verificado que a ausência de um sistema de coleta e tratamento de esgoto sanitário expõe o manancial subterrâneo ao risco de ser contaminado por nitrato, além de microrganismos patogênicos (GASPAROTTO, 2006; SILVA, 2001). Outras fontes, como áreas cultivadas com hortaliças também podem estar contribuindo para a degradação dessa fonte de abastecimento de água e comprometendo os seus usos preponderantes. No entanto, ações como a melhoria das condições sanitárias e a orientação dos proprietários das hortas para dimensionar quantidades de fertilizantes podem evitar ou reduzir a deterioração da qualidade da água.

\section{CONSIDERAÇÕES FINAIS}

Os resultados do estudo realizado ao longo do ano em amostras de água dos poços localizados nas proximidades da horta demonstram que a atividade de cultivo de hortaliças contribui para alterar as características da água subterrânea conforme resultados de nitrato $26,2 \mathrm{mg} / \mathrm{L}$, poço 3 . Foi possível observar também que as boas características construtivas dos poços minimizam a contaminação pontual da água subterrânea, mas é pouco eficiente no controle da contaminação por fontes difusas, assim como sugere os resultados do estudo desenvolvido em uma área cultivada com hortaliças.

$\mathrm{O}$ pH e oxigênio dissolvido da água nos pontos estudados pouco variaram de uma estação a outra, e o teste estatístico apontou que não há evidência para supor que a sazonalidade influa nos valores de $\mathrm{pH}$. As baixas concentrações de oxigênio dissolvido em água são características das águas da região e não necessariamente são indicativos de contaminação.

Os parâmetros monitorados $\mathrm{CE}, \mathrm{NO}_{3}{ }^{-}$e $\mathrm{NO}_{2}{ }^{-}$apresentaram variabilidade entre as estações chuvosa e seca, com valores superiores na estação seca. Suas maiores concentrações foram verificadas nos pontos localizados próximos à horta e indicam a influência desta atividade nos valores destes parâmetros. Em estudos futuros nessa área sugere incluir o parâmetro fósforo, pois este é utilizado nos fertilizantes e seu excesso incorpora-se à água de percolação e, por conseguinte às águas subterrâneas. 


\section{AGRADECIMENTOS}

Os autores expressam os seus agradecimentos ao CNPq pelo apoio financeiro e a Secretaria de Meio Ambiente e Agricultura municipal de Ji-Paraná (SEMAGRI), bem como ao Departamento de Engenharia Ambiental (UNIR) pela ajuda oferecida nas análises em seus laboratórios.

\section{REFERÊNCIAS}

ALABURDA, J.; NISHIHARA, L. Presença de composto de nitrogênio em águas de poços. Rev de Saúde Pública, v.32, n. 2, p. 531-7, 1998.

APHA. Standard Methods for the Examination of Water and Wastewater. Washington: APHA, 1995.

BRASIL. Ministério da Saúde. Portaria no 518 de 25 de março de 2004. Estabelece normas e o padrão de potabilidade da água destinada ao consumo humano. Diário Oficial da União, Brasília, v. 59, p. 266-270, 26 mar. 2004, Seção 1.

CHOWDARY, V.M.; RAO, N.H.; SARMA, P.B.S. Decision support framework for assessment of nonpoint-source pollution of groundwater in large irrigation projects. Agricultural Water Management, 2005. p. 94-225.

FUNASA - Fundação Nacional de Saúde. Manual de Saneamento. 3. ed. Brasília: ASCOM/PRESI/FUNASA/MS, 2004.

GASPAROTTO, P. H. G.; ROCHA, C. S.; GRECELLÉ, C. B. Z. Quantificação de coliformes totais e fecais pela técnica do NMP em amostras de água do município de Ji-Paraná. Rev Ciência e Consciência. v. 2, n.1, 2006.

LEITE, N. K., et al. Groundwater quality comparison between rural farms and riparian wells in the western Amazon, Brazil. Química Nova. v.34, n.1, p. 11-15, 2010.

LUZ, G. L. et al. A questão do nitrato em alface hidropônica e a saúde humana. Ciência Rural. v.38, n. 8, p. 2388-2394, 2008.

MELO, J. G.; VASCONCELOS, M. B.; Morais, S. D. Aspectos hidrogeológicos e de qualidade da águas no aquífero Barreiras na bacia do Rio Jacu-RN. Rev de Geologia. v.20, n. 20, p. 231-241, 2007.

MIRLEAN, N.et al. O impacto industrial na composição química das águas subterrâneas com enfoque de Consumo humano (Rio Grande, RS). Química Nova.v. 28, n. 5, p. 788-791, 2005.

MORAIS, P. R. C. Mapa hidrogeológico do Estado de Rondônia: texto explicativo. Porto Velho: CPRM - Serviço Geológico do Brasil; 1998. 40 p.

MS - Ministério da Saúde. < http://www.saude.gov.br./>. 05 jan. 2011.

PESSOA, M.C.P.Y.et al. Identificação de áreas de exposição ao risco de contaminação de águas subterrâneas pelos herbicidas atrazina, diuron e tebutioron. Pesticidas: Rev. ecotoxicologia e meio ambiente. v.13, p. 111-122, 2003.

RESENDE, A. V. Agricultura e qualidade da água: Contaminação da água por nitrato. Planaltina: Embrapa Cerrado, 2002. 
SILVA, A. C. et al. Impacto físico-químico da deposição de esgotos em fossas sobre as águas de aqüífero freático em Ji-Paraná- RO. Rev. de estudos ambientais.v.11, n.2, p. 101-112, 2009.

SILVA, A. C; DOURADO, J. C. Contaminação de aquífero freático por fossas domésticas. In: SIMPÓSIO DA ENGENHARIA AMBIENTAL: ENERGIA E MEIO AMBIENTE, 1. Anais... Ji-Paraná, 2008.

SILVA, A. C. Estudo da contaminação do lençol freático através da integração de técnicas geofísicas e geoquímicas em Ji-Paraná- Ro. 153 f. 2008. Tese (Doutorado em Geociências e Meio Ambiente).

Universidade Estadual Paulista. Rio Claro.

SILVA, A. C. Potabilidade das Águas Subterrâneas do Município de Ji-Paraná. Estudo de Caso:

Bairro Nova Brasília. 91 f. 2001. Dissertação (Mestrado em Geociências). Universidade Estadual Paulista. Rio Claro. 